\title{
Deciphering vanished scripts
}

\section{The origins of communication are explored in a landmark compilation that charts the disappearance of writing systems from ancient cuneiform to Turkish Arabic script, explains Andrew Robinson.}

\author{
The Disappearance of Writing \\ Systems: Perspectives on Literacy and \\ Communication \\ Edited by John Baines, John Bennet and \\ Stephen Houston \\ Equinox: 2008. 384 pp. $€ 65.00$
}

For more than 3,000 years, hieroglyphs were used to write the language of ancient Egypt. Then the script disappeared from use. The latest known hieroglyphic inscription was carved by a priest into the gate of Hadrian on the Egyptian island of Philae at Aswan on 24 August AD 394. Knowledge of how to read the hieroglyphs vanished in late antiquity and had to be recovered in the eighteenth and early nineteenth centuries, deciphered with the help of the newly discovered Rosetta Stone. By opening up the world of ancient Egypt before early Greek and Hebrew records, scholars doubled the time span of accessible history.

Archaeologists, epigraphists and linguists have for centuries puzzled over the origins of written communication, especially the alphabet. Less studied is the disappearance of longestablished ancient writing systems, such as Egyptian hieroglyphs, Mesopotamian cuneiform and Mayan glyphs, an exception being the Chinese characters that continue to flourish after some 3,000 years. Yet, "writing systems that have been lost are often better understood than those for which we try to establish their process of formation", concludes Egyptologist John Baines in The Disappearance of Writing Systems, a landmark collection of articles by scholars. "Their loss may be just as revealing as their first appearance."

A modern example is Kemal Atatürk's 1928 abolition of the Arabic script from the Turkish language. He replaced it with the Latin script as part of his drive to bring Turkey closer to European culture. Today, few Turks can read Ottoman Turkish in Arabic script, and soon the ability will reside only with scholars. In centuries to come, Baines imagines, this combination of script and language may disappear too and need to be deciphered.

Although separated widely in time, these Egyptian and Turkish script disappearances share a common element: a seismic shift in political power and cultural prestige that caused the adoption of a new writing system. Pharaonic Egypt was conquered in the fourth

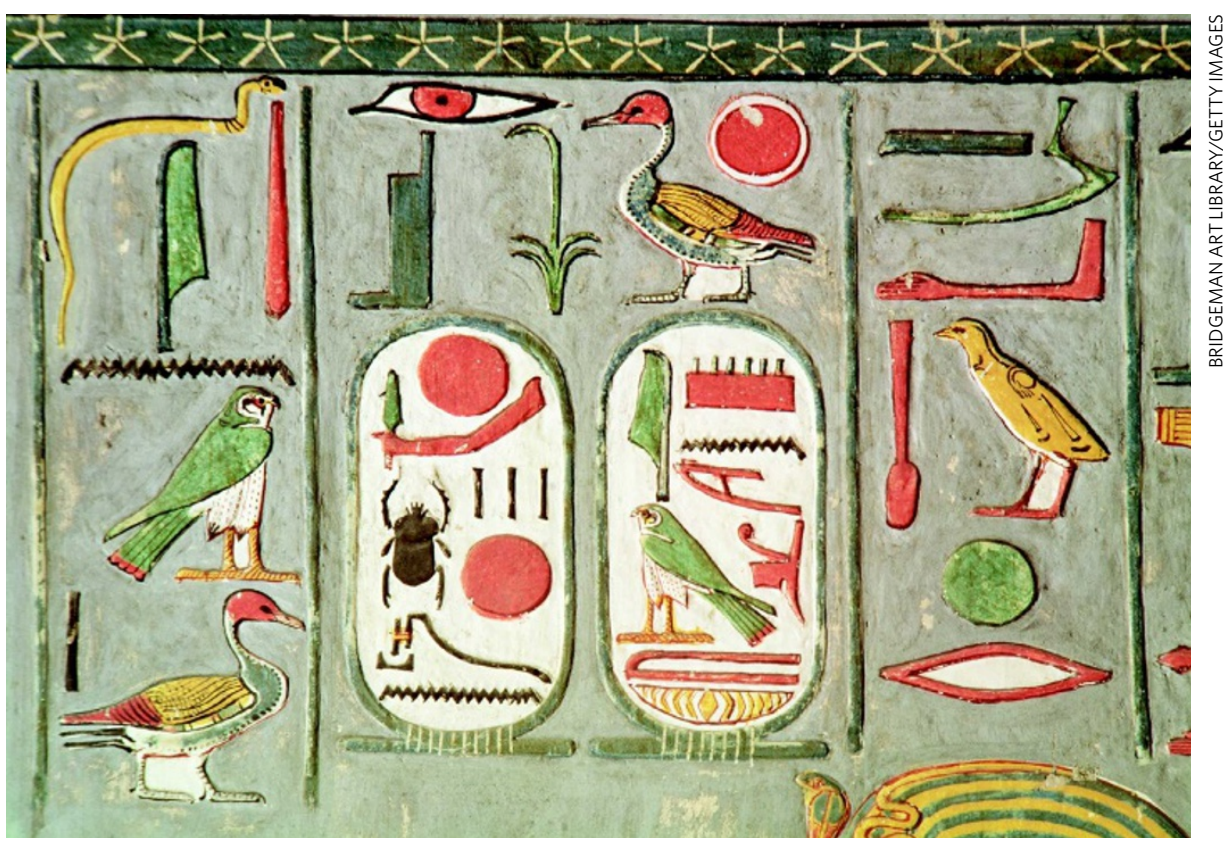

Hieroglyphs fell into obscurity because of political, religious and language changes in Egypt.

century вс by Alexander the Great and was ruled by the Greek-speaking Ptolemy dynasty, which used an alphabet - hence the inscription of the Greek alphabet on the Rosetta Stone in 196 вC along with the hieroglyphs. However, unlike in Turkey, the Egyptian script was not abolished. Instead, the hieroglyphs were slowly marginalized by a flux of politics, language, script and religion. After the death of Cleopatra in 30 BC, Egypt became a province of the Roman Empire, which wrote in Latin script. The spread of Christianity gave rise to the Egyptian Coptic Church, which wrote in Coptic script, and in the seventh century AD, Egypt was conquered by Arabs writing in the Arabic script of Islam. These changes together fossilized the hieroglyphs.

The book came out of the first major conference to focus on the disappearance of ancient writing systems, held in 2004 in Oxford, UK, and organized by the three editors. Baines is professor of Egyptology at the University of Oxford and well known for his work on literacy in ancient Egypt. John Bennet of the University of Sheffield, UK, is an expert on the Aegean scripts, notably Linear A and B, and Stephen Houston of Brown University in Rhode Island has been instrumental in the Maya decipherment revolution since the 1980 s.
It is a pioneering, fascinating and authoritative book. The 17 contributors cover a surprising range of topics in detail and with comprehensive bibliographies. They discuss familiar lost scripts such as cuneiform, and more obscure examples, including the Kharosthi script of northwest India, the Meroitic script of Nubia in what is now northern Sudan, Aztec and Mexican pictography, the knottedcord quipus of the Inca empire and its Andean successors, and the Manchu script of China, which fell out of favour with the end of the Qing dynasty in 1912 but was revived in the 1980s. Inevitably there are omissions, most regrettably the much-debated Rongorongo script of Easter Island in the southeastern Pacific, a script that probably flourished for less than 100 years until its rapid disappearance in the mid-nineteenth century.

David Brown's accessible essay on the increasing redundancy of cuneiform in Babylonia (now southern Iraq) after the Persian conquest of 539 BC offers a good case study of the multiple, often interdependent, causes of script obsolescence. Cuneiform, written in wedge-shaped signs on clay with a reed stylus, was used for three millennia before the first century AD to write many languages of the Middle East: Sumerian, Babylonian, Assyrian, Old Persian 
and others, rather like today's use of the Latin script to write European languages. Brown advances economic, linguistic and administrative arguments for the gradual disappearance of cuneiform from its former heartland around Babylon, the capital of Babylonia.

Economically, Babylon declined in importance when Alexander's alleged plan to make the city the capital of Asia failed to transpire after his death in 323 вс. The city was also bypassed to the north by new desert trade routes from Asia to the Med-

iterranean, which opened up with the domestication of the camel as a pack animal. The use of Babylon's cuneiform script therefore diminished in commercial transactions.

Linguistically, Babylonian cuneiform was disadvantaged in comparison with alphabetic scripts. It was cumbersome, requiring hundreds of signs - a mixture of syllables and word symbols known as

logograms - and used a clay medium. Unlike the alphabets used to write Greek, Phoenician and Aramaic, Babylonian cuneiform could not be written rapidly, cursively or conveniently with a brush on papyrus or other lightweight materials. Nevertheless, cuneiform was sometimes adapted to write alphabets. Such was its prestige that the Persian conquerors of Babylon invented a new cuneiform alphabet for their own language, now known as Old Persian.

Administratively, however, the Persian empire preferred the Aramaic script to any kind of cuneiform. Originally a Semitic language of ancient Syria, Aramaic had become the lingua franca of the Middle East by the sixth century BC. Later, it was the vernacular language of Jesus Christ and the Apostles and is used in the Dead Sea Scrolls. Aramaic eventually displaced cuneiform, which found its last refuge in astrology. Brown tells how scribes working in the collapsing temples of Babylon still, as late as the first century AD, "exploit[ed] a shrinking market for old-fashioned Babylonian astrology in cuneiform", even though they no longer wrote in an elegant hand.

The Aramaic script was itself extinguished in the seventh century AD by the Arabic script, which developed from Aramaic via the script of the Nabataeans, who ruled from Petra in Jordan. Arabic eliminated many pre-existing South Semitic alphabets that had been invented by literate but bored desert nomads in the Arabian peninsula before the arrival of Islam - a subtle process that is well explained in Michael Macdonald's essay. The association of the Arabic script with the prestige of Islam and the Koran was the determining factor in its triumph.

In south Asia, by contrast, a unifying script has not been important. Most modern Indian scripts derive from one ancestor, Brahmi, first attested in the third century $\mathrm{BC}$ in the rock edicts of Ashoka at various sites in Pakistan and northern India. Yet Sanskrit, the language of the Hindu scriptures, has been written in many Indian scripts, including south Indian Grantha and Devanagari. Similarly, the Pali language of Buddhist scriptures is written in the Sinhala, Thai, Burmese and Khmer scripts, among others. This availability of alternatives, says Richard Salomon in his essay, explains why the early Kharosthi script - probably an Indian derivative of Aramaic - could be abandoned with the decline of the Kushan empire that used it, despite its use in Sanskrit and Buddhist texts between the third century BC and the third century AD. Perhaps because of the country's pluralistic traditions, India has chosen not to define its culture by a single script, unlike China and the Arab world.

One wonders whether China's enduring political unity may partly account for the longevity of Chinese characters, a subject that is somewhat neglected by the book. The classical Chinese script enjoys high respect because of its antiquity - it is descended from the recognizable characters inscribed on 'oracle bones' of the Shang civilization from 1200 BC - and because of its imperial and artistic associations. When the former Chinese leader Mao Zedong, himself a calligrapher, proposed to romanize the Chinese script in the 1950s to educate the masses, he was forced by the literati to compromise with the introduction of a simplified character script and a parallel romanized phonetic system known as Pinyin. In Japan, several thousand Chinese characters were integrated with two sets of indigenous syllabic signs during the first five centuries AD to make one prestigious writing system. Despite the difficulties of writing Chinese and Japanese, neither script looks likely to disappear any time soon under the onslaught of alphabetic triumphalism.

The Disappearance of Writing Systems reveals that commerce, culture, language, medium, power, prestige and religion, in varying combinations, are all implicated in the disappearance of scripts. Each languagescript combination raises issues that cannot be understood from linguistic considerations alone. We know more about script death than script birth, but no single theory can encompass why scripts flourish or vanish.

Andrew Robinson is a visiting fellow of Wolfson College, Cambridge CB3 9BB, UK, and author of The Story of Writing and Lost Languages: The Enigma of the World's Undeciphered Scripts. e-mail:ar471@cam.ac.uk

\section{New look at cancer drugs}

\section{Durchleuchtet \\ Artpoint 222, Vienna, Austria \\ 25 October until 27 November 2008}

Margaret Oechsli goes on extraordinary journeys with her microscope. Peering at a smudge of a dried chemical, such as crystallized glutamic acid, she probes the refracted light looking for artistic inspiration. "I have no control over what I see in the microscope," she says in a rich Polish accent. But what she finds and photographs is stunning. She has created more than 3,000 images, shimmering geometries and colourful landscapes that look more like paintings than photos.

Oechsli's abstract studies of microscopic chemical structures will be shown in a new exhibition called Durchleuchtet, starting this week at Artpoint 222 in Vienna. Each image explores a cancer drug - such as tamoxifen, oxaliplatin, herceptin and others - that Oechsli handles in her day job as a clinical research coordinator in the Heart and Lung Institute at Jewish Hospital in Louisville, Kentucky.

The medical theme complements the fund-raising goal of Durchleuchtet - which in German means both 'illuminated with light' and 'X-rayed'. Oechsli's photos will be auctioned alongside artistically rendered radiographs of Austrian athletes, and the proceeds will benefit the charity Médecins Sans Frontières (Doctors Without Borders).

Although her background in science has 